\title{
Intralesional interferon alfa-2b treatment of condylomata acuminata previously resistant to podophyllum resin application
}

\author{
J M BOOT, F B BLOG, E STOLZ \\ From the Department of Dermatovenereology, University Hospital Rotterdam-Dijkzigt, Rotterdam, The \\ Netherlands
}

SUMMARY The safety and efficacy of intralesionally administered interferon alfa- $2 \mathrm{~b}$ were assessed in 11 patients suffering from condylomata acuminata for four to 10 months for whom application of podophyllum resin had proved unsuccessful. Three warts from each patient were injected with $10^{6} \mathrm{IU}$ interferon alfa- $2 b$ three times a week for three weeks. Treatment was followed by a 13 week observation period.

Interferon alfa- $2 b$ treatment resulted in a highly significant $(\mathrm{p}<0.0001)$ reduction in the mean size of the treated warts, which decreased from an initial size of $29 \mathrm{~mm}^{2}$ to $2-3 \mathrm{~mm}^{2}$ by week 16 . In six out of the 10 patients completing the trial, both the test condylomata and adjacent control warts cleared completely; a recurrence was observed in one of these six patients. Influenza like symptoms (headache and myalgia) were the most common side effects reported, though they were mild in nature and not disabling. These results corroborate those of previous trials with interferon preparations and indicate that its antiviral activity makes it a possible treatment for this sexually transmitted disorder.

Condyloma acuminatum, or the genital wart, is a common sexually transmitted disorder that is characterised by papillomatous lesions occurring on the mucus membrane or skin of the external genitalia as well as in the perianal region. These tumours are known to be caused by a human papillomavirus (HPV), especially types 6, 11, 16, and $18 .^{1-3}$ Evidence also exists of a strong association between HPV types 16 and 18 and the malignant transformation of condylomata in the vulva and cervix. ${ }^{2-5}$

Treatment of genital viral warts has proved difficult despite the wide variety of ablative and chemical methods available, such as surgical excision, laser treatment, cryosurgery, electrocauterisation, use of antimitotic agents, and application of podophyllum resin. These methods of treatment are often painful, may cause unwanted side effects and scarring, and are often associated with recurrence. ${ }^{167}$ No form of treatment has yielded consistently effective results.

In contrast, recent trials have indicated promising results after using human recombinant interferon.-10

Address for reprints: Dr E Stolz, Department of Dermatovenereology, University Hospital Rotterdam-Dijkzigt, Dr Molewaterplein 40, 3015 GD Rotterdam, The Netherlands

Accepted for publication 25 June 1988
We therefore sought to assess the safety and efficacy of intralesionally injected interferon alfa- $2 b$ in patients suffering from genital warts, singling out those in whom podophyllum resin treatment had hitherto proved unsuccessful.

\section{Patients and methods}

ENTRY CHARACTERISTICS

Men and women patients aged 18 to 65 and diagnosed as having condylomata acuminata that had proved resistant to podophyllum resin treatment were eligible for inclusion in the trial. The patients were required to be in good general health and to have no history of heart disease, thrombophlebitis, pulmonary embolism, or known sensitivity to any component of the test medication. Women participants were required to be non-pregnant and using a reliable contraceptive method. Patients who had received local or systemic antiviral or antiwart treatment two weeks before the onset of the study or who had undergone cytotoxic or immunosuppressive treatment four weeks before the start of the trial were ineligible to participate. Previous treatment with interferon or interferon inducers also constituted grounds for exclusion. Patients were asked not to take, during the trial, any medication that could 
interfere with interferon alfa- $2 b$ or modify the natural course of the disease. Informed consent was obtained from all patients before entry.

\section{STUDY DESIGN AND DATA EVALUATION}

Three warts on each patient were injected intralesionally with $10^{6} \mathrm{IU}$ interferon alfa-2b (Intron A, Essex/ Schering) three times a week for three weeks. Clinical efficacy was assessed by measuring the areas of the treated condylomata and comparing the evolution of their mean area with that of two control warts (if present). The wart area was defined as the product of the two largest horizontal dimensions. Measurements were taken at each treatment visit as well as at weeks 4 , 6,12 , and 16 after the start of the trial.

Laboratory investigations, including blood chemistry and haematological examinations as well as routine urine analysis, were performed on days 1 and 5 and one week after the end of treatment.

A logarithmic transformation $(\log (\operatorname{area}+0.5))$ was applied to provide a better normally distributed variable. Analysis of variance with repeat measurements was employed for the first seven weeks to assess the significance of changes in the area of the treated warts. P values apply to this seven week period, after which relapse occurred in three patients.

\section{Results}

Ten out of the 11 patients entering the study success- fully completed the trial. The one patient who withdrew had difficulty in complying with the frequency of treatment visits; he did not experience any side effects while receiving treatment.

The treated patients (seven men and three women) were aged 19 to 55 (mean 35) years. Before the trial, podophyllum resin treatment had been unsuccessfully applied for periods ranging from four to 10 months.

Figure 1 shows the changes in wart area for each patient as well as the mean change during the trial. Intralesional injection of interferon alfa- $2 b$ resulted in a highly significant reduction $(\mathrm{F}$ value $=32 \cdot 72 ; \mathrm{p}<$ 0.0001 ) in the mean area of the treated condylomata, which decreased from $29 \mathrm{~mm}^{2}$ to $12 \mathrm{~mm}^{2}$ by day 21 , and to $2-3 \mathrm{~mm}^{2}$ by week 16 . The reduction in wart area was especially noteworthy between days 19 and 21 (p $<0.0001), 21$ and $24(p=0.0069)$, and 24 and $26(p<$ 0.0001 ).

In six out of the 10 patients, both the test and control condylomata cleared completely (fig 2 ). The test warts disappeared by day 24 (one patient), day 26 (three patients), between weeks four and seven (one patient), and between weeks seven and 12 (one patient). By contrast, the condylomata remained refractory in four patients (two men and two women). A relapse was observed in one woman: all her condylomata had cleared by day 26 , but one lesion reappeared during the eighth week at a site that had been injected. In two patients (one man and one woman) condylomata that had shrunk in size began

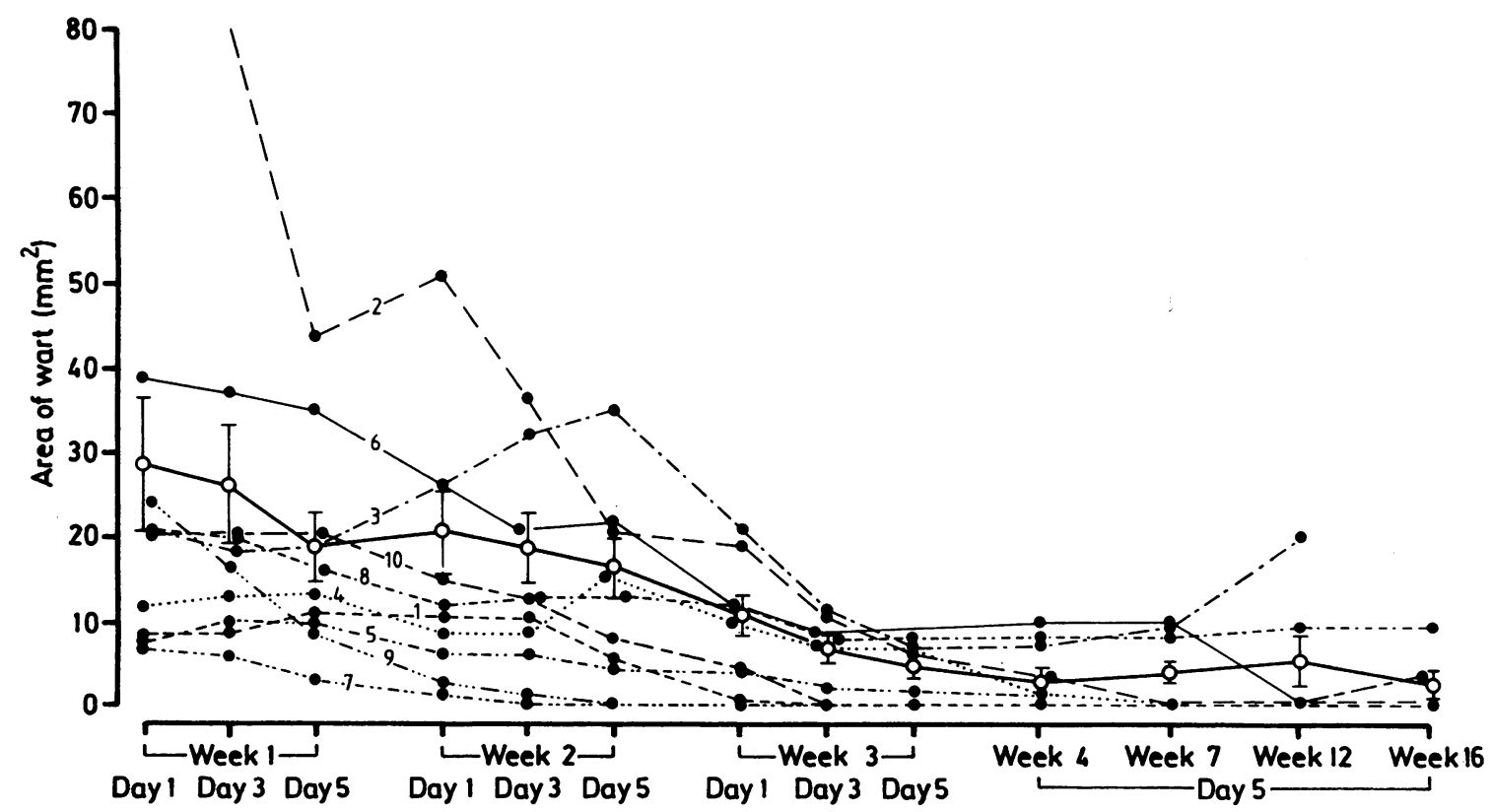

Fig 1 Changes in mean wart area $(O)$ and for each of 10 patients (O) treated intralesionally with $10^{6}$ IU interferon alfa-2b three times a week for three weeks and followed up for 13 weeks. 

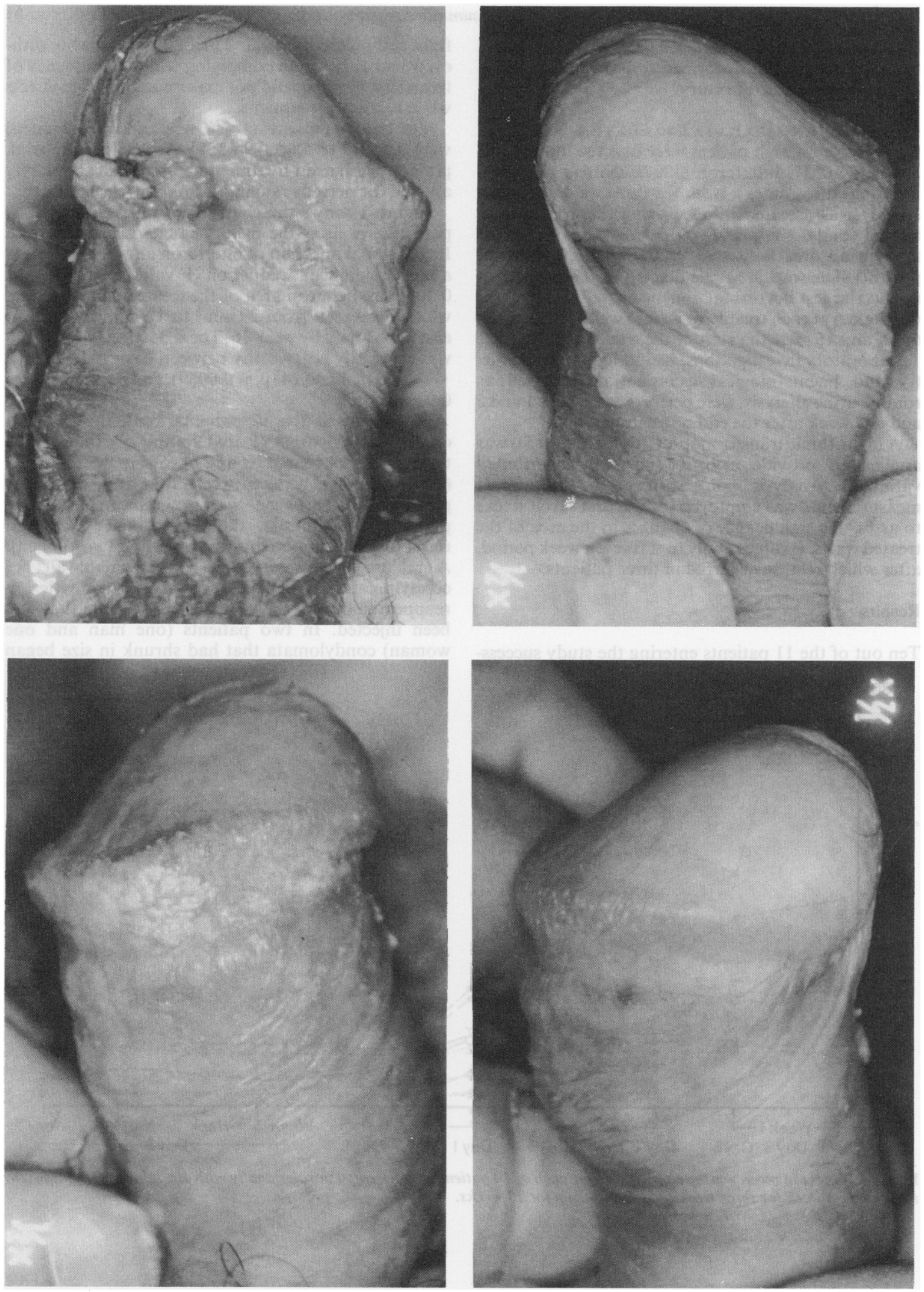

Fig 2 Disappearance of penile condylomata acuminata after intralesional treatment of two patients with $10^{6} I U$ interferon alfa-2b three times a week for three weeks. (Left, before treatment; right, after treatment). 
Table Side effects that emerged during treatment of genital warts with $10^{6} \mathrm{IU}$ interferon alf $a-2 b$ three times $a$ week for three weeks

\begin{tabular}{ll}
\hline Side effects & No of patients \\
\hline Influenza like symptoms & 6 \\
Headache & 4 \\
Muscle ache & 4 \\
Irritation at injection site & 2 \\
Malaise & 2 \\
Nausea & 1 \\
Pain in kidney region & 1 \\
Myalgia & 1 \\
\hline
\end{tabular}

increasing again (in week 7 and week 12).

Side effects are listed in the table. Six patients reported influenza like symptoms, four experienced muscle ache, and four headache. Two were free of symptoms and three reported mild, persistent side effects throughout most of the three week treatment period. In no case, however, were symptoms severe enough to cause withdrawal from the study. Laboratory variables remained essentially unaltered.

\section{Discussion}

In this study of 11 patients, the intralesional administration of interferon alfa- $2 b$ for three weeks proved to be effective in eliminating or reducing most of the genital warts treated, which confirms results from previous preliminary or double blind placebo controlled studies. ${ }^{8-15} \mathrm{~A}$ total cure, however, only occurred in five patients in whom the positive effects of treatment were maintained for 13 weeks after intralesional injection of the interferon preparation. One out of the six patients whose lesions had disappeared suffered a relapse during the study period.

Though adjacent warts were not measured, interferon treatment also seemed to reduce non-treated lesions next to the treated warts during and after interferon treatment. Further testing as to whether HPV might also be affected in the tissues adjacent to the lesions is warranted.

No serious or severe side effects attributable to interferon alfa- $2 b$ were reported by any of the patients. The reactions were generally characterised by mild influenza like symptoms, headache, or muscle pain, and did not interfere substantially with the patients' daily activities. None of the patients considered subcutaneous interferon injections with a fine needle (16 $\times 0.5 \mathrm{~mm}$ ) to be inordinately painful.

Several different treatment regimens for intralesional and intramuscular administration of interferon alfa- $2 b$ have been used to treat con- dylomata acuminata, which have resulted in differing degrees of success. The results achieved have also depended on the duration of treatment and the length of the follow up period. ${ }^{8-15}$ Although the injection of interferon alfa-2b can be effective in treating genital warts, additional studies must be performed to optimise doses and treatment schedules. In the meantime, intralesional injection of interferon alfa-2b may be considered to be one of the possible treatments for this sexually transmitted disease.

This study was supported by a grant from Essex Nederland. We thank Mr and Mrs F Shapiro (Syntaxis-Belgium) for editorial and technical help with the manuscript.

\section{References}

1 Bunney MH. Viral warts: their biology and treatment. New York: Oxford University Press, 1982:1-99.

2 Lutzner MA. The human papillomavirus. Arch Dermatol 1983; 119:631-5.

3 Crum CP, Ikenberg H, Richart RM, Gissmann L. Human papillomavirus type 16 and early cervical neoplasia. $N$ Engl $J$ Med 1984;310:880-3.

4 Coggin JH Jr, zur Hausen H. Workshop on papilloma viruses and cancer. Cancer Res 1979;39:545-6.

5 Baird PJ. Serological evidence for the association of papillomavirus and cervical neoplasia. Lancet 1983;ii:17-8.

6 Margolis S. Therapy for condylomata acuminata: a review. Rev Infect Dis 1982;4suppl:S829-36.

7 Shumer SM, O'Keefe EJ. Bleomycin in the treatment of recalcitrant warts. J Am Acad Dermatol 1983;9:91-6.

8 Eron $\mathrm{LJ}$, Judson $\mathrm{F}$, Tucker $\mathrm{S}$, et al. Interferon therapy for condylomata acuminata. $N$ Engl J Med 1986;315:1059-64.

9 Gross G, Roussaki A, Schopf E, De Villiers EM, Papendick U. Successful treatment of condylomata acuminata and bowenoid papulosis with subcutaneous injections of low-dose recombinant interferon-alpha. Arch Dermatol 1986;122:749-50.

10 Vance JC, Bart BJ, Hansen RC, et al. Intralesional recombinant alpha-2 interferon for the treatment of patients with condylomata acuminata or verruca plantaris. Arch Dermatol 1986; 122:272-7.

11 Einhorn N, Ling P, Strander H. Systemic interferon alpha treatment of human condylomata acuminata. Acta Obstet Gynecol Scand 1983;62:285-7.

12 Marcovici R, Peretz BA, Paldi E. Human fibroblast interferon therapy in patients with condylomata acuminata. Isr J Med Sci 1983;19:104.

13 Gall SA, Hughes CE, Weck P, Wisnant J. Interferon for the treatment of resistant condylomata acuminata. Gynecol Oncol 1984;17:264.

14 Geffen JR, Klein RJ, Friedman-Kien AE. Intralesional administration of large doses of human leukocyte interferon for the treatment of condylomata acuminata. J Infect Dis 1984;150: 612-5.

15 Schonfeld A, Nitke S, Schattner A, et al. Intramuscular human interferon-B injections in the treatment of condylomata acuminata. Lancet 1984; i: 1038-42. 